\title{
Total Mesorectal Excision
}

National Cancer Institute

\section{Source}

National Cancer Institute. Total Mesorectal Excision. NCI Thesaurus. Code C16180.

Surgery for rectal cancer involving precise removal of an intact mesorectal envelope with tumor-free margins. Associated with local recurrence rates below 5\% in clinical trials.

(from Medscape) 